\title{
Protective effect of zingiber officinale on mobile phone induced rat brain injury.
}

1. MBBS, M.Phil, MCPS-HCSM Assistant Professor Anatomy Hyderabad Institute of Medical and Allied Sciences.

2. MBBS

Research Scholar Jinnah Sindh Medical University.

3. MBBS, M.Phil

Professor Anatomy

Bahria University Medical \& Dental College Karachi.

4. BDS

Senior Lecturer Anatomy Jinnah Medical \& Dental College Karachi.

5. MBBS

Research Schola

Jinnah Medical \& Dental College Karachi.

6. MBBS, M.Phil

Professor Anatomy Jinnah Medical \& Dental College Karachi.

Correspondence Address:

Dr. Syed Alamdar Raza Zaidi Department of Anatomy

Hyderabad Institute of Medical and Allied Sciences.

syedalamdarrazazaidi@gmail.com

Article received on:

17/08/2021

Accepted for publication:

20/10/2021
Syed Alamdar Raza Zaidi', Mohammad Fawad Saeeduddin², Aisha Qamar ${ }^{3}$, Shabnam Khan ${ }^{4}$, Rozina Khan ${ }^{5}$, Syed Meesam Iftikhar Hussain Rizvi ${ }^{6}$

ABSTRACT... Objective: To observe the protective effect of zingiber officinale against radio frequency $(\mathrm{RF})$ radiation-induced oxidative stress on rat brain due to $3 \mathrm{G}$ mobile phone. Study Design: Prospective Experimental study. Setting: Department of Anatomy, BMSI, JPMC, Karachi. Period: January to March 2018. Material \& Methods: Twenty four healthy, adult, Albino rats, 3-4 months of age, weighing 150-300 gm were acquired. They were sorted into four groups. Group A was marked as control, Group B was exposed to 3G mobile phone $2100 \mathrm{MHz}$ radiation 24 hours daily, Group $\mathrm{C}$ was exposed to same dose of radiation as group $\mathrm{B}$ along with zingiber officinale $250 \mathrm{mg} / \mathrm{kg} /$ day orally, and Group D was given same dose of zingiber officinale as in group $\mathrm{C}$. The rats were euthanized at end of study period after recording their final weight. Brain of rats was removed and weighed. It was processed for haematoxylin and eosin stain to observe general morphology of cerebellum. Results: The data displayed an insignificant increase in final body weight and absolute brain weight in group B animals as compared to control, whereas an insignificant increase and insignificant decrease was observed in body weight and absolute weight of brain when group $\mathrm{C}$ was compared with group $\mathrm{B}$ respectively. Microscopic examination of cerebellum in $\mathrm{H}$ \& E stained sections revealed distortion of cellular architecture in group B as compared to control. Tissue sections from group C demonstrated significant restoration of cerebellar architecture. Results of group D were similar to control. Conclusion: Cell phones emit radiation causing damage to brain, especially cerebellum, however, concurrent use of ginger significantly ameliorates this damaging effect.

Key words: $\quad$ Brain, Cell Phone, Radiation, Zingiber Officinale.

Article Citation: Zaidi SAR, Saeeduddin MF, Qamar A, Khan S, Khan R, Rizvi SMIH. Protective effect of zingiber officinale on mobile phone induced rat brain injury. Professional Med J 2021; 28(12):1797-1803. https://doi.org/10.29309/TPMJ/2021.28.12.6752

\section{INTRODUCTION}

Brain is the most important organ of human body as it controls all other functions. If any damage to this vital organ occurs, every organ is in turn affected. Brain injury can be the result of a wide range of internal as well as environmental factors. ${ }^{1}$ Rapid advancement of communication technology has brought a marked change in every individual's life. The use of cellular phones gradually began to increase from the mid - 1990s, and it has become an essential part of life in many countries. All walks of life such as buying groceries, selling goods, etcrequires help from mobile phones. Cell phones expose people to high-frequency electromagnetic fields. ${ }^{2}$

Thus safety is a valid interest for those who use cell phones, especially, in respect to probable damage resulting from radiofrequency electromagnetic radiations. People are increasingly worried regarding possible damaging effects on health due to exposure to radiofrequency radiations, like those emitting from cellular phones. ${ }^{3}$ The mobile or cell phones make the use of "radiofrequency radiation" which differs worldwide. The common range of these frequencies is $900-2200 \mathrm{MHz}$. 3G cell phones work on a good bandwidth and a high speed for transmission of data and process different multimedia applications on internet. ${ }^{4}$

Biological effects of radiofrequency radiation released by a cell phone have aroused the minds of researchers. Several researches have concluded that the daily and prolong use of 
microwave devices, particularly mobile phones, can have a deleterious effect on biological system, specially on brain, because the electromagnetic force source is kept in close proximity to the head of the user. While talking on cellular phone, a mobile phone generates radio frequency electromagnetic radiation which can penetrate 40-60 $\mathrm{mm}$ deep into the human brain. ${ }^{5}$ This results in damage to neurons, blood brain barrier is disturbed and some reports also suggest that it also plays a part in the development of brain tumors. ${ }^{6}$

Research has been underway for using plants for treating ailments and one of such herb widely used is ginger. Zingiber officinale (ginger) belongs to family Zingiberaceae has been widely used in treating flu and sore throat. It has been shown that ginger oil is effective in protecting DNA damage induced by hydrogen peroxide. The dried extract of ginger has antioxidants like gingerols and shogoals. In addition it also contains monoterpenes and sesquiterpenes, and phenolic ketone derivatives. ${ }^{7}$ Ginger has also been observed to have anti- oxidant effects and found to have protective and therapeutic effects in Alzheimer's disease. ${ }^{8}$ In vitro, oxidative stress at cellular level, Fas expression and caspase-3,$8,-9$ activation due to exposure to ultraviolet $B$ rays were reduced due to pre-treatment with ginger. Ginger also decreased expression and transactivation of COX-2 due to ultraviolet B rays. ${ }^{9}$

With this background, this research was conducted to assess the effects of $2100 \mathrm{MHz}$ electromagnetic radiation emitted by $3 \mathrm{G}$ mobile phone on rat brain, with possible protection provided by concomitant use of Zingiber officinale.

\section{MATERIAL \& METHODS}

This prospective experimental study was undertaken from $10^{\text {th }}$ January 2018 at Anatomy department of Basic Medical Sciences Institute (BMSI), Jinnah Postgraduate Medical Center (JPMC), Karachi for eight weeks after receiving ethical approval from the institutional ethical review committee (F.1-2/2018/BMSI-E.COMT/067/ JPMC). Twenty four healthy adult albino rats of either sex, ranging in age from 3-4 months, with weight between 150-300 gm were procured from the animal house of BMSI, JPMC. The animals were observed for one week before the start of the study by providing them with standard laboratory food and 12-hour day and night cycle, and water ad libitum. Their health status was assessed by their food intake and activity. The animals were sorted into four groups on basis of treatment.

Group A was assigned as control, Group B was given $3 \mathrm{G}$ mobile phone $2100 \mathrm{MHz}$ radiation 24 hours daily, Group C was exposed to the same dose of radiation along with zingiber officinale $250 \mathrm{mg} / \mathrm{kg}$ body weight/day orally, and Group D was given same dose of zingiber officinale as in group $\mathrm{C}$ only. It was used as negative control to make sure that ginger itself does not cause any harm to the experimental animals. The animals were weighed, numbered and housed in the cages under laboratory conditions. Two animals of similar gender were placed in one cage. Mobile phone was suspended about 4 to $5 \mathrm{~cm}$ from cage floor with the assistance of wire. Suggested experimental dose of $3 \mathrm{G}$ mobile phone $2100 \mathrm{MHz}$ radiation was placed near the animals cages through mobile phones (Telenor Easy 3G, Model: W2) and protection was given by zingiber officinale $250 \mathrm{mg} / \mathrm{kg}$ body weight/day according to experimental dose. The animals were weighed at the end of study period, and sacrificed by giving ether anesthesia in a glass container. They were then fixed to a dissecting board.

Parietal approach was used for dissecting out brain. Scalp was cut by a midline incision extending from occipital to nasal region by the iris scissor. Scalp-flaps were laterally reflected and fixed. Iris scissor was used to cut inter-parietal and parieto-occipital sutures through lambda. Parietal and occipital bones were removed. From the posterior aspect of neck, lamina of $1^{\text {st }}$ cervical vertebra was cut to expose and separate spinal cord from the brain stem, so that brain could be removed from cranial cavity. After recording the weight of brain with digital electronic balance, it was placed in $10 \%$ formal saline for fixation for 24 hours. ${ }^{10}$ Then a $2 \mathrm{~mm}$ square from cerebellum was cut and processed in ascending grades of alcohol. Tissue infiltration was done with paraffin 
at $58^{\circ} \mathrm{C}$ in laboratory oven and paraffin blocks were made. 4 micron thick sections were sliced on rotary microtome. Then tissue sections were placed in water bath at $42^{\circ} \mathrm{C}$ and taken up on albumenized glass slides. Tissue was fixed on hot plate at $30-32^{\circ} \mathrm{C} .{ }^{10}$ Staining of cerebellar tissue was carried out with Haematoxylin and Eosin $^{10}$ for observing its morphology. Quantitative data that is body weight and absolute brain weight were analyzed with Statistical Package for Social Science (SPSS) software, version 21.The quantitative differences between the treated and control groups were assessed by paired sample student " $t$ " test. Statistically significant difference was considered if $p$-value was equal to or less than 0.05 .

\section{RESULTS}

The mean values of initial and final body weight (gm) of animals in groups A, B, C and D were $232.46 \pm 13.17$ and $252.78 \pm 14.96,223.50 \pm 5.16$ and $275.83 \pm 12.05,252.67 \pm 12.02$ and 279.98 \pm 10.85 and $253.83 \pm 6.11$ and $278.97 \pm 6.12$ respectively (Figure-1). A significant increase was observed between initial and final body weight of animals in control group $\mathrm{A}$ and $\mathrm{C}$, where as highly significant increase was observed in rats belonging to group $B$ and $D$. An insignificant increase was observed when final body weight of ginger with $3 \mathrm{G}$ mobile phone treated groups C was compared with final body weight of $3 \mathrm{G}$ mobile phone radiation treated group $B$.

The mean values of absolute weight of brain in group A, B, C and D were $2.09 \pm 0.04,2.21 \pm$ $0.07 \mathrm{gm}, 2.07 \pm 0.05 \mathrm{gm}$ and $2.00 \pm 0.03 \mathrm{gm}$ respectively (Figure-2). An insignificant increase in absolute brain weight was seen in radiation treated group $B$ when compared to control group A, where as an insignificant decrease was observed on comparing mean absolute brain weight of group $C$ animals receiving ginger with radiation as compared to group $B$ treated with $3 G$ mobile phone radiation only.

When Haematoxylin and eosin stained 5 micron thick sections of rat cerebellum were examined under microscope, they revealed highly organized architecture, with outer grey matter and inner white matter. The cerebellar cortex comprised of the three layers; outer molecular, inner granular, and middle Purkinje cells layer consisting of single layer of pyriform- shaped neurons (Figure-3). The molecular layer revealed few neuron cell bodies with ample number of axons. Large, flask-shaped Purkinje cells were observed in middle layer arranged in a single row. Innermost granular layer displayed a large accumulation of small neurons (Figure-3). Cerebellar tissue taken from group $B$ treated with $3 G$ mobile phone (2100MHz radiation 24 hours daily) animals stained with $\mathrm{H}$ and $\mathrm{E}$ demonstrated reduced thickness of cerebellar cortex (Figure-4). There was diminution of molecular as well as granular layer and population of Purkinje neurons was also decreased. The examination of $\mathrm{H}$ and $\mathrm{E}$ stained tissue from cerebellum of group $C$ animals which were treated with ginger along with $3 G$ mobile phone radiation revealed restoration of the three layers of cerebellar cortex to a marked extent (Figure-5). White matter was also restored almost similar to control. The microscopic findings of Hand $E$ stained tissue sections of cerebellum in group D were similar to control.

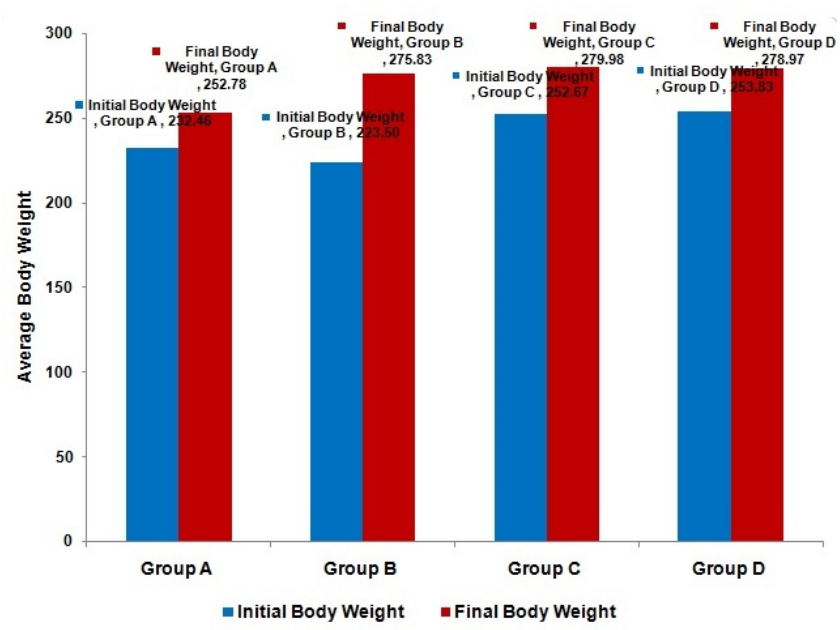

Figure-1. Comparison betweeninitial and final body weight (gm) in different groups of Albino rats.

Group $A=$ Control, $B=3 G$ radiation treated, $C=$ $3 G$ radiation + Zingiber officinale, $D=$ Zingiber officinale.

Group $A=$ Control, $B=3 G$ radiation treated, $C=$ $3 G$ radiation + Zingiber officinale, $D=$ Zingiber officinale. 


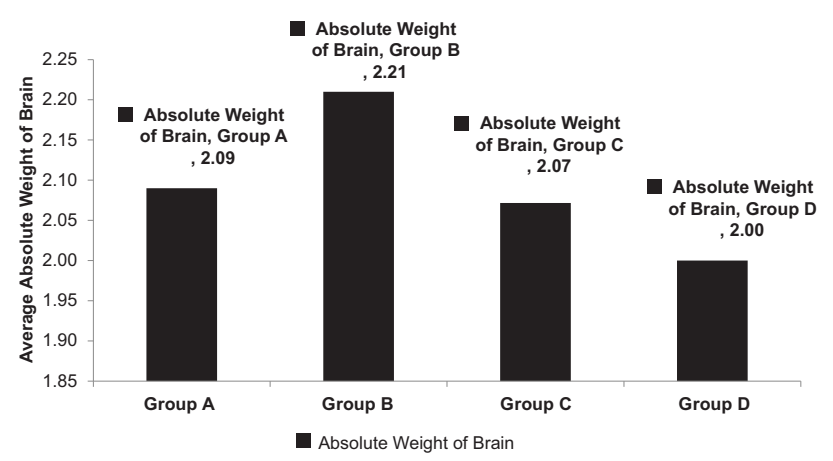

Figure-2. Comparison between absolute weights (gm) of brain in different groups of Albino rats.

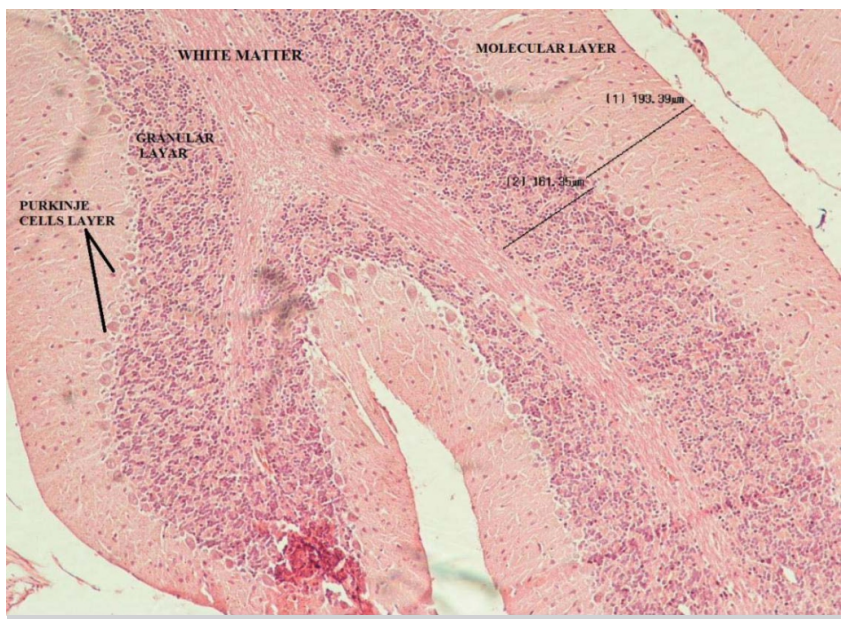

Figure-3. $4 \mu \mathrm{m}$ thick, $H$ and $E$ stained section from control rat (group A) cerebellum showing intact architecture with molecular layer, Purkinje cell layer, granular layer and white matter (Photomicrograph X100).

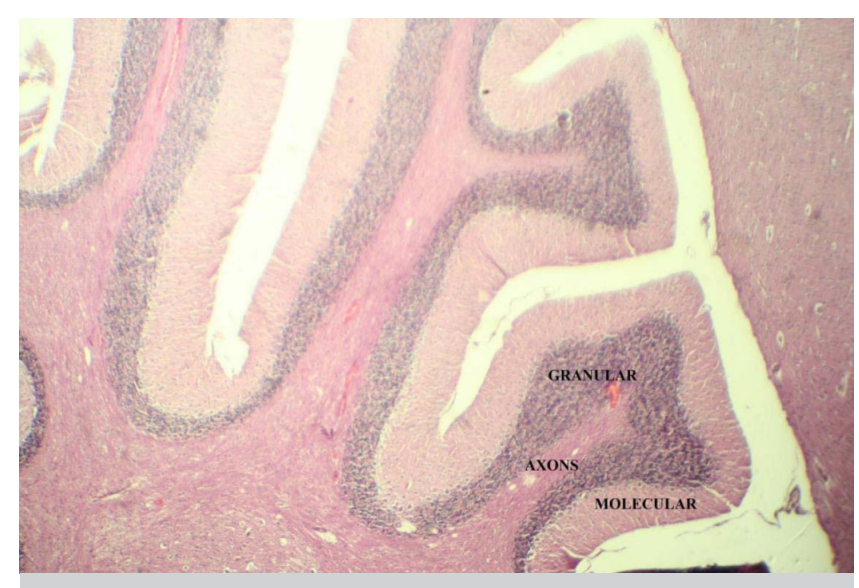

Figure-4. $4 \mu \mathrm{m}$ thick, $\mathrm{H}$ and $\mathrm{E}$ stained section of group $B$ radiofrequency radiation treated rat cerebellum showing disruption of architecture, with molecular layer, decreased thickness in granular layer and white matter (Photomicrograph X 100).

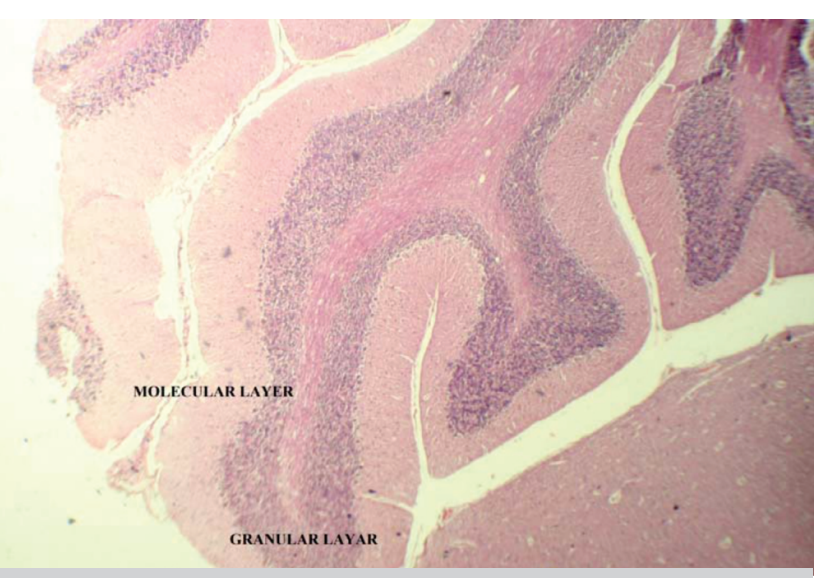

Figure-5. $4 \mu \mathrm{m}$ thick, $\mathrm{H}$ and $\mathrm{E}$ stained section from cerebellum of group $\mathrm{C}$ animal (radiofrequency radiation with ginger treated) showing improvement in architecture of cerebellum and restoration in thickness of molecular and granular layers (Photomicrograph X 100).

\section{DISCUSSION}

Mobile phones have become an indispensable part of every individual's life today as a necessary means of connection and information exchange. $3 G$ is one of most commonly used network. The electromagnetic radiation of this cellular network causes harm to human health and can even lead to major public health issues, so effects of cell phone radiation are being investigated widely throughout the world. ${ }^{11} 3 \mathrm{G}$ cell phones use 2100 $\mathrm{MHz}$ radiofrequency. They emit increased amount of electromagnetic radiation because they work on a higher frequency as compared to previous networks. They can also discharge continuous electromagnetic radiation to the surroundings. ${ }^{12,13}$

Brain is one of the most vital organs of body, which unfortunately is more prone to damage by the harmful effects of electromagnetic radiation (EMR) released by mobile phones due the close proximity of cell phones to it during calls. The cerebellum was selected for this experimental study because it is one of the most essential parts of the brain. It has been demonstrated that during the regular use, $3 G$ mobile phones discharge EMR which are absorbed into the brain of the person using it and interrupt its functions. ${ }^{14}$ Brain tissue is also highly susceptible to oxidative damage because of its high consumption oxygen and its under developed antioxidative defense 
mechanisms. ${ }^{1}$

Keeping this in view, the current study was planned to observe the preventive effect of Zingiber officinale on brain damage caused by radiation in albino rats.

Animals in the groups A, B C and D gained weight during the study period. This demonstrated that rats in groups $B$ and $C$ tolerated electromagnetic radiation well throughout the study period. There was insignificant increase in final weight in radiation treated groups $\mathrm{B}$ and $\mathrm{C}$ in comparison with control group $A$. The results of the current research were in accordance to another study ${ }^{15}$ who reported increase in the body weight of all the groups of albino male Wistar rats in which group A and group B were exposed to mobile phone radiation for 8 hours and 4 hours per day respectively for 8 weeks, whereas group $\mathrm{C}$ was taken as control.

There was an increase in the absolute weight of brain in radiofrequency irradiated animals of group B in comparison with control. This was similar to Rodgers et al (2016) ${ }^{16}$ who discovered significant increase in brain weight of male Wistar rats after giving a single dose of 20 Gy radiotherapy as compared to control. This showed that experimental animals tolerated radiation well as also shown by their body weight and intake of diet. Another study ${ }^{17}$ tested this hypothesis by exposing the right sub ventricular zone (SVZ) by single dose of irradiation, and then intracranial injection of lysolecithin was given, which lead to de-myelinating lesions in the brain. The irradiated SVZ demonstrated an increased rate of proliferation after receiving injection, and the neuro blastsderived from SVZ spread from the irradiated site toward the area of the lesion leading to formation of chain-like structures. The treated half of brain showed increased number of developing oligodendrocytes which were incorporated into the area which showed demyelination and synthesized new myelin, thus supporting the view that neuronal stem cells are resistant to radiation injury to some extent and can recover a neurogenic niche."
The gross examination of cerebellum in $\mathrm{H}$ \& $E$ stained tissue of irradiated group $B$ animals showed decreased thickness of cerebellar cortex. The Purkinje neurons displayed dystrophic changes. This was most likely due to the enhanced number of free radicals emitted by the mobile phone generated electromagnetic field intensifying peroxidation of lipids, which lead to oxidative stress in brain cells. Reactive oxygen species (ROS) can cause severe harm to cellular macromolecules, particularly DNA. There seems to be a direct relationship between the excess production of ROS and DNA damage elicited by electromagnetic radiation. A likely mechanism of interaction between the biological systems and radiofrequency generated electromagnetic radiation (RF-EMR) is involvement of free radical. ${ }^{18}$ These findings were in agreement to another study ${ }^{19}$ who also observed marked degenerative changes, scanty cytoplasm and pyknotic nuclei in the neurons of frontal cortices of male Sprague-Dawley rats exposed to different doses of electromagnetic radiation, ranging from 900$2450 \mathrm{MHz}$. Ali Sangi et al (2020) ${ }^{1}$ also observed completely distorted architecture of cerebellum with thinning of molecular layer and disruption of granular layer in male Wistar rats exposed to mobile phones for 8 weeks.

$\mathrm{H}$ and $\mathrm{E}$ stained sections of group $\mathrm{C}$ animals who received ginger in addition to radiofrequency radiation revealed restoration of all three layers of cerebellar cortex to a significant extent. White matter was also restored, similar to control. This was most likely due to the antioxidant effect of ginger which protected cerebellum from oxidative stress caused by radiofrequency electromagnetic radiation emitted by cell phones. Other studies have also demonstrated that phytochemicals such as zingerone and dehydrogingerone in ginger protect mice against sickness and death caused by radiation; free radical scavenging, anti-inflammatory and antioxidant effects of ginger impart the observed protection. ${ }^{20}$ This finding was in agreement to Ali Sangi et al $(2020)^{1}$ who used male Wistar rats and treated them with $50 \mathrm{IU} / \mathrm{kg}$ body weight vitamin $\mathrm{E}$ for 4 weeks in addition to exposure to mobile phones. They observed that brain parenchyma was 
partially preserved with undamaged architecture. The pyramidal cells appeared within normal limits. Alsherbiny et al $(2019)^{21}$ proposed that phytochemicals present in ginger exert protective effects against different insults via different mechanisms and cell signalling pathways, such asWnt/B-catenin, Nrf2/ARE, NF- $7 B$, MAPK, ERK/ CREB and TGF- $\beta 1 /$ Smad3. Bassiouny et al $(2016)^{22}$ also observed improvement in cellular architecture with augmented number of Purkinje cells, and increased thickness of granular layer in cerebellum of STZ-induced adult male albino rats which received $500 \mathrm{mg}$ of ginger $/ \mathrm{kg} /$ day orally for 6 weeks, as compared to STZ- treated control which revealed disruption of architecture of cerebellar cortex, degeneration of Purkinje cells and reduced thickness of granular layer.

\section{CONCLUSION}

The results of the present study have shown that use of mobile phones causes oxidative damage to the brain, especially cerebellum. However, concomitant use of anti-oxidants such as ginger ameliorates this damaging effect to a marked extent. Thus the need of the day is to educate people to use natural dietary supplements in their diet such as ginger in order to protect it from the damaging effects of radiofrequency electromagnetic radiation emitted by mobile phones.

\section{Copyright@ 20 Oct, 2021.}

\section{REFERENCES}

1. Ali Sangi SM, Bawadekji A, Alotaibi NM, Aljameeli AM, Soomro S. Protective effects Vitamin E on mobile phone induced injury in the brain of rats. International Journal of Pharmaceutical and Psychopharmacological Research 2020; 10 (1): 97-104 (elJPPR).

2. Leng $L$. The relationship between mobile phone use and risk of brain tumor: A systematic review and meta-analysis of trails in the last decade. Chin Neurosurg Jl 2, 38 (2016). https://doi.org/10.1186/ s41016-016-0059-y.

3. Tyagi A, Duhan M, Bhatia D. Effect of mobile phone radiation on brain activity GSM Vs. CDMA. International Journal of Science Technology \& Management 2011; 2(2), www.ijstm.com.
4. Aydogan F, Unlu i, Aydin E, Yumusak N, Devrim E, Samim EE, Ozgur E, Unsal V, Tomruk A, Ozturk GG, Seyhan N. The effect of $2100 \mathrm{MHz}$ radiofrequency radiation of a $3 \mathrm{G}$ mobile phone on the parotid gland of rats. American journal of otolaryngology, $2015 \mathrm{Feb}$ 28; 36(1):39-46.

5. Kesari KK., Siddiqui M, Meena R, Verma HN, Kumar $S$. Cell phone radiation exposure on brain and associated biological systems. Indian Journal of Experimental Biology, 2013; 51 (3): 187-200.

6. Dogan $M$, Turtay MG, Oguzturk $H$, Samdanci $E$, Turkoz Y, Tasdemir S, Alkan A, Bakir S. Effects of electromagnetic radiation produced by $3 \mathrm{G}$ mobile phones on rat brains: Magnetic resonance spectroscopy, biochemical, and histopathological evaluation. Human \& experimental toxicology., 2012 Jun 1;31(6):557-64.

7. Kamel MA. Study on DNA damage and oxidative stress and some biochemical alterations of long term administration of Alpha-2 Delta (a2-ס) ligand Pregabalin and possibility of Zingiber Officinale in ameliorating these Effects in rats. World Journal of Pharmaceutical Research 2016; 5(8): 1528-45. DOI: 10.20959/wjpr20168-6850.

8. Ali Sangi SM, Al Jalaud NA. Prevention and treatment of brain damage in streptozotocin induced diabetic rats with Metformin, Nigella sativa, Zingiber officinale and Punica granatum. Biomed. Res. Ther. 2019; 7 (6): 3274- 85.

9. Mishra RK, Kumar A, Kumar A. Pharmacological activity of Zingiber officinale. International Journal of pharmaceutical and chemical sciences. 2012; $1(3): 1073-8$.

10. Bancroft JD, Gamble M. Theory and practical of histological techniques. 6th ed. Edinburg: Elsevier Churchill Livingstone; 2008: 25-7,136-8.

11. Li F, Chang J, Lv Y, Xu D, Chen J, Sun X. Impact of electromagnetic irradiation produced by $3 G$ mobile phone on brain neurotransmitters in mice during growth and development period. Biomedical Research, 2017; 28 (14): 6220-24.

12. Bhargava S, Motwani MB, Patni VM. Effect of handheld mobile phone use on parotid gland salivary flow rate and volume. Oral Surg Oral Med Oral Pathol Oral Radiol 2012; 114:200-6.

13. Gultekin DH, Moeller L. NMR imaging of cell phone radiation absorption in brain tissue. Proceedings of the National Academy of Sciences, 2013; 2;110(1):5863. 
14. Negm SA, Abd El-Hady AM, Yassen NY, Nagm A. Cerebellar histopathological and histochemical alterations induced by electromagnetic field exposure of mice. Journal of Bioscience and Applied Research 2017; 3(1):45-60.

15. Usikalu MR, Rotimi SO, Oguegbu AE. Effect of Exposure of $900 \mathrm{MHz}$ radiofrequency radiation on rat brain. European Journal of Experimental Biology. 2012; 2(6):2499-504.

16. Rodgers SP, Zawaski JA, Sahnoune I, Leasure JL, Gaber MW. Radiation-induced growth retardation and microstructural and metabolite abnormalities in the hippocampus. Neural Plast. 2016; 2016:3259621. doi:10.1155/2016/3259621.

17. Capilla-Gonzalez V, Cebrian-Silla A, Guerrero-Cazares H, Garcia-Verdugo JM, Quiñones-Hinojosa A. The generation of oligodendroglial cells is preserved in the rostral migratory stream during aging. Front. Cell. Neurosci. 2014; 7:147-51.

18. Kesari KK, Meena R, Nirala J, Kumar J, Verma HN. Effect of $3 \mathrm{G}$ cell phone exposure with computer controlled 2-D stepper motor on non-thermal activation of the hsp27/p38MAPK stress pathway in rat brain. Cell Biochemistry and Biophysics, 2014 Mar; 68(2):347-58. DOI: 10.1007/s12013-013-9715-4.
19. Eser O, Songur A, Aktas C, Karavelioglu E, Caglar V, Aylak F, Ozguner F, Kanter M. The effect of electromagnetic radiation on the rat brain: An experimental study. Turk Neurosurg. 2013; 23(6):707-15.

20. Baliga MS, Haniadka R, Pereira MM, Thilackchand KR, Rao S, Arora R. Radioprotective effects of Zingiber officinale Roscoe (Ginger): Past, present and future. Food Function, 2012; 3 (7): 714-23.

21. Alsherbiny MA, Abd-Elsalam WH,El badawy SA, Taher E, Fares M, Torres A, Chang D, Li CG. Ameliorative and protective effects of ginger and its main constituents against natural, chemical and radiation-induced toxicities: A comprehensive review. Food and Chemical Toxicology, 2019; 123: 72-97.

22. HS Bassiouny, NAW Ahmed, Yousry MY, Hisham NM. Comparative histological study on the effect of ginger versus a-lipoic acid on the cerebellum of a male albino rat model of induced diabetes. The Egyptian Journal of Histology, 2016; 39 (4): 341-52(12)DOI: https://doi.org/10.1097/01.EHX.0000512117.56425.37.

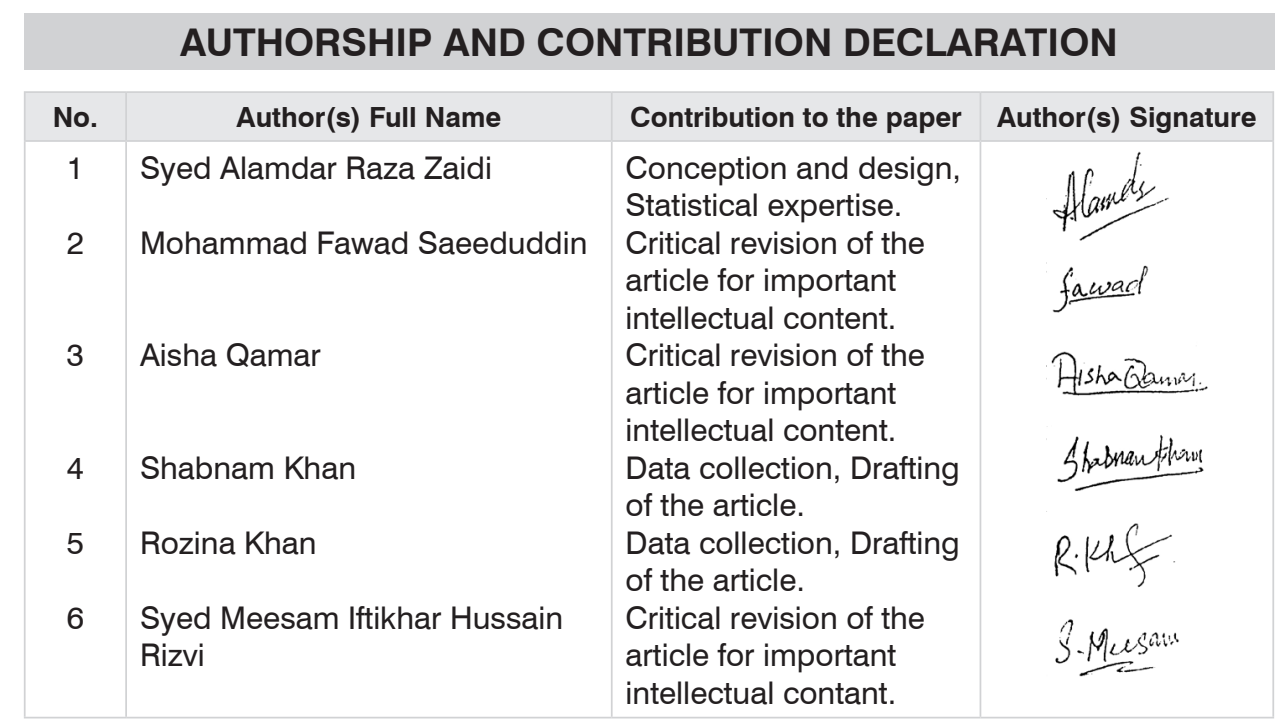

